\title{
Rechtsunsicherheiten bei internationalen elektronischen Handelsgeschäften
}

Ihre Reduktion unter Berücksichtigung des deutschen, US-amerikanischen und internationalen Vertragsrechts

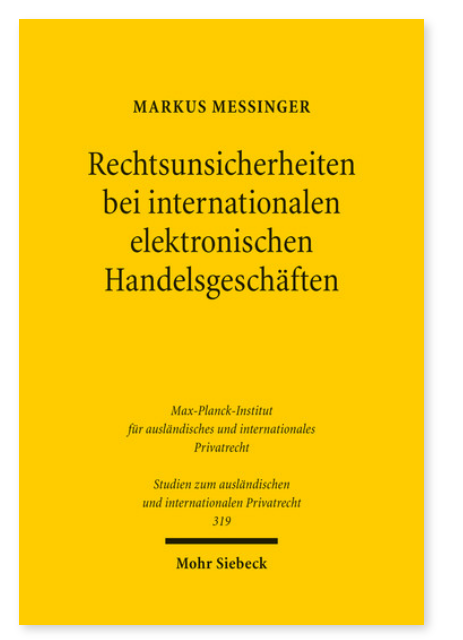

2014. XXXVI, 541 Seiten. StudIPR 319

ISBN 978-3-16-153361-7

DOI 10.1628/978-3-16-153361-7

eBook PDF 114,00€

ISBN 978-3-16-153360-0

fadengeheftete Broschur 114,00€
Die Globalisierung der Märkte und die Informatisierung von Transaktionen verändern die Anforderungen an die rechtlichen Rahmenbedingungen für Geschäfte zwischen Unternehmen. Markus Messinger analysiert und bewertet die deutschen, USamerikanischen und internationalen Rechtsvorschriften für elektronische B2B-Verträge und entwickelt alternative Lösungen. Zunächst gibt er einen Überblick über die ökonomischen und technischen Merkmale elektronischer Handelsgeschäfte und die ökonomische Funktion rechtlicher Regelungen. Anschließend prüft er im Detail die Effizienz der bestehenden Rechtsregeln im IZVR, IPR und Vertragsrecht zur Reduktion von Rechtsunsicherheiten im internationalen elektronischen Handelsverkehr. Auf dieser Basis werden Vorschläge ökonomisch effizienter Regelungen unterbreitet, die der Bewertung des »United Nations Convention on the Use of Electronic Communications in International Contracts« dienen.

Markus Messinger wurde für diese Arbeit der Fakultätspreis der Juristischen Fakultät der Leibniz Universität Hannover verliehen.

Markus Messinger Geboren 1981; Studium der Rechtswissenschaften an der Leibniz Universität Hannover;

wissenschafterlicher Mitarbeiter am Institut für Rechtsinformatik, Leibniz Universität Hannover; Forschungsaufenthalt an der Northwestern University, Chicago; Referendariat in Hamburg; 2013 Promotion; seit 2010 Rechtsanwalt in Frankfurt am Main.
Jetzt bestellen:
https://mohrsiebeck.com/buch/rechtsunsicherheiten-bei-internationalen-elektronischen-handelsgeschaeften-
9783161533617 ?no_cache=1
order@mohrsiebeck.com
Telefon: $+49(0) 7071-923-17$
Telefax: $+49(0) 7071-51104$ 